\title{
IV \\ PERÍCIA SOCIAL NAS DISPUTAS JUDICIAIS DE GUARDA: \\ CONTRIBUIÇÕES DAS RELAÇÕES SOCIAIS DE GÊNERO SOBRE IGUALDADE PARENTAL*
}

Rita C. S. Oliveira ${ }^{1}$

\section{Introdução}

$\mathrm{Na}$ esteira da transformação sócio histórica dos modos de ser famílias, com a promulgação da Lei da Guarda Compartilhada (2008, 2014) e da Lei de Alienação Parental (2010), o Judiciário vem sendo cada vez mais demandado a decidir aspectos da privacidade familiar.

A atuação profissional na Justiça de Família ocorre majoritariamente em um cenário de relações familiares conflitivas advindas da separação conjugal, em que predominam as disputas de guarda de filhos(as) e os pedidos de limitação/proibição/ampliação do convívio com a pessoa que não tem a guarda. Sem a clareza acerca da contribuição específica da profissão, tal contexto favorece o olhar psicologizante para tais fenômenos e a emissão de juízos de valor sobre ser mãe/pai ${ }^{2}$, como cuidar e se relacionar com filhos(as).

Foi desse lugar, como pesquisadora e profissional, inquieta com o silêncio teórico ${ }^{3}$ sobre o trabalho da(o) assistente social nessas demandas, que nos desafiamos a discutir as dimensões sociais postas nos litígios familiares judicializados, para qualificar a realização do estudo/perícia social ${ }^{4}$ que é demandado como subsídio para as decisões judiciais. Mas não se trata de tarefa fácil, pois nesse espaço, ainda que se possa analisar que a ausência do Estado, em al-

*DOI - 10.29388/978-65-86678-28-4-0-f.91-112

${ }^{1}$ Assistente social no judiciário paulista. Mestre e Doutora em Serviço Social pela Pontifícia Universidade Católica - PUCSP. Pesquisadora sobre as particularidades da profissão na área sociojurídica.

${ }_{2}$ Embora as famílias formadas por dois pais ou duas mães também vão se fazendo presentes nas disputas de guarda de filhos, utilizaremos pai e mãe por representarem a grande maioria.

${ }^{3}$ Iamamoto (2004) utiliza essa expressão para se referir as produções do Serviço Social na área sociojurídica.

4 Neste texto utilizaremos estudo/perícia social e relatórios/laudos/pareceres sociais como sinônimos. 
guma medida, possa ser determinante para a emergência do processo judicial, o confronto se dá objetivamente entre pessoas e não entre elas e o Estado.

Fávero (2009) alerta que ao realizarmos um estudo social estabelecemos relações com indivíduos ou grupos que, como sujeitos históricos, vivem situações concretas, construídas socialmente. A realidade socioeconômica e cultural desses sujeitos é a base do estudo social. Compete-nos compreender sua inserção na família, no trabalho, nas políticas sociais, no território e na cultura. Isso significa mais do que identificar a constituição e o histórico familiar, a ocupação em relação ao trabalho, os rendimentos, a escolaridade, o acesso a serviços de habitação, saúde, educação e assistência social, entre outros. Implica em “[...] desvelar a realidade social em suas conexões e determinações mais amplas e [...] interpretá-la com o apoio de conhecimentos científicos pertinentes à área e tomar uma posição do ponto vista do Serviço Social". (FÁVERO, 2009, p. 611)

Por meio da realização de cursos sobre estudos/perícias sociais com oficinas de relatórios/laudos sociais, como docente, tem sido possível compreender que o desafio do Serviço Social é o de realizar registros que expressem a articulação entre as dimensões teórico-metodológicas e ético-políticas da profissão, produzindo não apenas relatos descritivos, na lógica da razão instrumental, mas análises sociais que extrapolem o imediato dos fenômenos.

Ao tomarmos como pressuposto o interesse da criança como superior, levando em conta também o interesse de seu pai e sua mãe, passamos a considerar importante nos qualificarmos para a análise da desigualdade de poder presente nas relações conjugais e parentais. Entretanto, diante da ênfase das produções teóricas do Serviço Social sobre a categoria classe social, o estudo sobre as relações de gênero e, também, sobre as relações raciais, não vinha fazendo parte de nossa rotina de estudos e pesquisas.

Para este texto, retomamos algumas ponderações realizadas em Gois e Oliveira (2019) sobre as armadilhas da profissão nas demandas da Justiça de Família e o olhar do Serviço Social sobre guarda compartilhada e alienação parental, para avançarmos na compreensão da desigualdade de gênero, com base na crítica feminista sobre tais legislações.

\section{Armadilhas e desafios da perícia social na justiça de família}

No exercício de reflexão sobre as particularidades do trabalho profissional nas demandas de disputa de guarda de filhas(os), Gois e Oliveira (2019) 
contextualizam que a implantação formal do Serviço Social na Justiça de Família em São Paulo (1979/1980) se deu num momento histórico da profissão em que ainda era predominante a perspectiva do Serviço Social de Caso, numa orientação positivista funcionalista, em grande parte ancorada em fundamentos teóricos psicossociais de matriz norte-americana. Com tal enfoque, era evidente a funcionalidade da profissão ao judiciário, estando alinhados os objetivos institucionais e os profissionais.

Passados quarenta anos dessa implantação, ocorreram profundas mudanças tanto na legislação como nos fundamentos teórico-metodológicos e ético-políticos da profissão. Como ensina Netto (1999), o projeto profissional "rema contra a maré" do projeto societário capitalista, do qual o judiciário é um importante representante. Temos, portanto, o tensionamento entre o projeto institucional e o profissional, o que exige da(o) assistente social, a compreensão dessa polaridade para realizar as mediações necessárias ao desenvolvimento de seu trabalho.

Ao assumir a fundamentação teórico crítica marxista como hegemônica, a matéria prima do Serviço Social passa a ser a questão social e suas expres sões. Iamamoto (2001) associa a questão social ao marco da contradição da relação capital-trabalho e da primazia da dimensão econômica na sociedade capitalista, mediatizada por disparidades entre as classes sociais, por relações de gênero, étnico-raciais e culturais, dimensões essas fundamentais para os estudos/ perícias sociais que envolvem conflitos familiares, espaço privilegiado da reprodução social.

Por estarem veladas pela subjetividade decorrente do conflito relacional e legal, muitas vezes, as expressões da questão social não se revelam no imediato dos conflitos judiciais, especialmente quando a pobreza e o não acesso a políticas sociais não sejam determinantes para o processo judicial. É aqui que se coloca uma armadilha profissional, como nos alerta Borgianni (2013), pois na aparência, o fenômeno que emerge e convoca nosso olhar é o da disputa de guarda (jurídico) e o do conflito relacional (com ênfase no emocional). (GOIS; OLIVEIRA, 2019, p. 26)

É importante considerarmos que com o legado histórico da abordagem individual psicologizante do Serviço Social e, ainda, a pouca produção de conhecimentos teóricos na perspectiva crítica sobre o trabalho profissional com famílias, não tem sido tarefa fácil realizar estudos/perícias sociais que superem o imediato e a singularidade dos fenômenos. Mioto (2010) afirma que o Serviço Social vem comportando esta contradição: ao mesmo tempo em que a profissão se constituiu numa área de conhecimento forte no campo da política social 
e na sua fundamentação teórico-metodológica e ético-política, fragilizou-se no debate sobre a temática da família e da intervenção profissional. Tendo em vista que as instituições continuaram a ser o principal campo de trabalho para as(os) assistentes sociais e, as famílias se mantiveram como sujeitos privilegiados de intervenção, sem o respaldo teórico na perspectiva crítica, além do empiricismo ocorreu a busca profissional por referências teóricas alheias às novas referências teórico-metodológicas da profissão.

Diante das características típicas dos processos judiciais de disputa de guarda de filhos(as), é recorrente o emaranhamento entre o objeto e o objetivo profissional e o institucional. Ao não distinguirmos a finalidade institucional da profissional, fica difícil reinterpretarmos a demanda à luz do projeto ético político, podendo incorrer em infração ética. Precisamos ter clareza sobre a contradição entre o projeto institucional e o profissional. Enquanto a lógica da instituição é binária, demandando respostas objetivas em busca de aferir a "verdade" de fatos, o Serviço Social se pauta na perspectiva metodológica marxiana da totalidade ${ }^{5}$, em busca das determinações socioeconômicas e culturais que constituem a complexidade da realidade social das famílias. Enquanto o judiciário

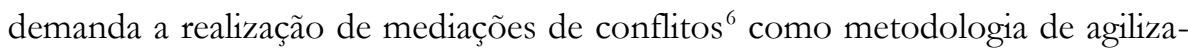
ção das lides judiciais por meio do consenso entre as pessoas envolvidas, cabe $\mathrm{a}(\mathrm{o})$ assistente social a complexa materialização do conceito teórico da mediação ${ }^{7}$ entre as dimensões da singularidade, da universalidade e da particularidade presentes na realidade social dos sujeitos.

É necessário ainda considerar que o trabalho profissional na perspectiva da proteção de direitos de crianças, adolescentes e adultos envolvidos nos processos judiciais também condensa a contradição da perspectiva punitiva presente na legislação e na forma de condução dos processos judiciais. Borgianni (2012) nos lembra que a inserção profissional nessa área nos coloca frente ao que intitula como "polaridade antitética" entre a proteção e a responsabilização, entretanto a polaridade a ser fortalecida é a da proteção. Afinal "no nosso Código de Ética, não há nenhum artigo que diga que a minha atribuição é responsabilizar civil ou criminalmente alguém. Isso é, porém, o que muitas vezes juízes e

\footnotetext{
5 A transcrição da palestra de Myrian Veras Baptista (2010) permite apreensão didática da categoria marxiana da totalidade.

${ }^{6}$ A Nota Técnica do CRESS-SP (2016) apresenta a Posição Preliminar sobre Serviço Social e Mediação de Conflitos, contrária a participação da(o) assistente social nessa atividade. Como decorrência, o judiciário paulista vedou essa prática.

${ }^{7}$ Paula (2015) realiza importante reflexão sobre a categoria marxiana da mediação nas perícias sociais.
} 
promotores estão tentando nos impingir no cotidiano". (GOIS; OLIVEIRA, 2019, p. 41)

Pesquisas do Serviço Social que abordam a guarda compartilhada e a alienação parental têm nos possibilitado avançar em nossas reflexões, que se mostram ainda mais necessárias em um contexto político no qual o Conselho Nacional de Direitos da Criança e do Adolescente - Conanda - propôs a revogação ${ }^{8}$ da Lei de Alienação Parental (2010) e caminham no Legislativo diferentes projetos de lei sobre o tema.

\section{A perspectiva do serviço social sobre guarda compartilhada e alienação parental}

Em alinhamento com a igualdade formal de direitos entre homem/pai e mulher/mãe estabelecidas na Constituição Federal (1988) e no Código Civil (2002), foi aprovada a Lei $n^{\circ} 11.698 / 2008$ de compartilhamento da guarda de filhas(os). Desde então, além da guarda unilateral, foi prevista a compartilhada, compreendida como "a responsabilização conjunta e o exercício de direitos e deveres do pai e da mãe que não vivam sob o mesmo teto, concernentes ao poder familiar dos filhos comuns".

Diante da pouca aplicação inicial dessa modalidade ${ }^{9}$, em 2014 foi aprovada a Lei no 13.058 que explicitou o significado "guarda compartilhada". Aparentemente, numa tentativa de direcionar sua aplicação, indicou que na falta de acordo entre os pais quanto à guarda dos filhos "[...] encontrando-se ambos os genitores aptos a exercer o poder familiar, será aplicada a guarda compartilhada, salvo se um dos genitores declarar ao magistrado que não deseja a guarda do menor" (art. 1.584, $\sqrt{ } 2^{\circ}$ ). Porém, o artigo 1.586 abre a possibilidade de o juiz, frente à existência de motivos graves, regular a guarda de outra maneira, de modo a preservar o bem estar dos filhos.

Em 2010, foi aprovada a Lei de Alienação Parental n 12.318 prevendo a aplicação de multa e inversão da guarda, caso se comprove a prática dos atos identificados a seguir: i) desqualificar a conduta do genitor no exercício da paternidade ou maternidade; ii) dificultar o exercício da autoridade parental; iii) di-

8 O motivo para que o Conanda se manifestasse sobre essa lei, oito anos após sua promulgação, foi a denúncia de mulheres/mães que perderam a guarda de filhos(as) e, por vezes, até mesmo o contato, após terem denunciado suspeita de abuso sexual por parte do pai.

9 Dados do IBGE (2017) registram que a guarda compartilhada passou de 16,9\% em 2016, para 20,9\% em 2017. 
ficultar o contato de criança ou adolescente com genitor; iv) dificultar o exercício do direito regulamentado de convivência familiar; v) omitir deliberadamente a genitor informações pessoais relevantes sobre a criança ou adolescente, inclusive escolares, médicas e alterações de endereço; vi) apresentar falsa denúncia contra genitor, contra familiares deste ou contra avós, para obstar ou dificultar a convivência deles com a criança ou adolescente; e, vii) mudar o domicílio para local distante, sem justificativa, visando a dificultar a convivência da criança ou adolescente com o outro genitor, com familiares deste ou com avós.

Embora seja importante conhecermos o debate sobre o histórico da lei, não discorreremos a esse respeito, devido ao distanciamento entre o conceito de síndrome da alienação parental e o objeto profissional do Serviço Social. A própria Psicologia, área mais relacionada ao tema, vem problematizando essa questão ao longo dos anos ${ }^{10}$. Essa incompatibilidade não significa, porém, a inexistência de dimensões sociais na realidade dos sujeitos cujos processos judiciais afirmem a ocorrência de alienação parental.

Enquanto são poucos os estudos e as pesquisas do Serviço Social sobre guarda compartilhada e alienação parental, temas que se inter-relacionam, é recorrente a dúvida sobre a pertinência de considerarmos a alienação parental como objeto profissional.

Retomando aspectos principais das referidas produções teóricas do Serviço Social podemos observar alguma divergência de posicionamento entre o autor Montaño (2016) e as autoras Lima (2016) e Batista (2016).

Lima (2016) e Batista (2016), trabalhando cotidianamente nas ações judiciais de guarda compartilhada e de alienação parental, foco de suas pesquisas, trazem a contextualização sócio histórica das transformações familiares e a discussão do projeto ético político. Ambas realizaram pesquisa de campo com assistentes sociais que também trabalham no judiciário. Montaño (2016), assistente social, acadêmico e pesquisador sobre temas mais amplos da profissão, tomou a alienação parental e a guarda compartilhada como objeto para a pesquisa bibliográfica, a partir do seu papel paterno (MONTAÑO, 2016, p. 18).

As autoras e o autor convergiram ao considerar a alienação parental como objeto profissional. Entretanto, as autoras enfatizam sua articulação com a convivência familiar, direito fundamental de crianças e adolescentes, conceito este que consideramos mais apropriado como objeto profissional por ser constitutivo da convivência social e da proteção social.

${ }^{10}$ Há recente discussão, com diferentes pontos de vista, na publicação "Debatendo sobre Alienação: diferentes perspectivas", do Conselho Federal de Psicologia - CFP (2019). 
O autor enfatiza a importância da(o) assistente social manifestar em seu parecer social a ocorrência (ou não) de atos de alienação parental, ponderando que o coletivo profissional deve assumir o compartilhamento da guarda como pauta em defesa da igualdade parental. A seu ver, a guarda compartilhada é a que representa a pauta feminista.

Conhecedoras da dinâmica do contraditório nos processos judiciais, as autoras e os sujeitos de suas pesquisas (também assistentes sociais no judiciário) são reticentes quanto à pertinência do parecer social afirmar sobre a ocorrência de atos de alienação parental, sugerindo-se a menção, se for o caso, de indicativos de limitação no convívio familiar. Quanto à guarda compartilhada, que também foi objeto da pesquisa de Lima (2016), a autora entende que não pode ser generalizada como propõe o autor.

Observamos que Montaño (2016), Lima (2016) e Batista (2016) apesar de abordarem, com maior ou menor ênfase, a transformação histórica social dos papéis do homem/pai e da mulher/mãe, não trazem fundamentação teórica sobre a categoria relações sociais de gênero. Tal questão referenda o distanciamento já mencionado da profissão em considerar gênero como uma categoria analítica da realidade social.

Essa reflexão nos remeteu à Hümmelgen e Cangussú (2017), pesquisadores da área do Direito, que abordam a insensibilidade ao gênero e a suposta neutralidade do Direito e das formulações teóricas pautadas em ideias abstratonormativas, em geral sem pesquisa de campo com os sujeitos afetados pelas decisões judiciais. A partir da análise de textos e doutrinas jurídicas sobre alienação parental, identificaram opiniões homogêneas que se repetem e reproduzem estereótipos sobre a mulher, sintetizados em três imagens: i) a mãe egoísta e controladora; ii) a ex cônjuge ciumenta e vingativa e iii) a alienadora mentirosa e paranoica. Ponderam que, apesar disso, a linguagem usada para se referir à pes soa que aliena é a da suposta neutralidade do gênero masculino.

Para o autor e autora, essa é uma expressão da insensibilidade ao gênero ${ }^{11}$ quanto às formas distintas do homem e da mulher vivenciarem o mesmo fenômeno, ao se levar em conta os papéis sociais, a valorização cultural de cada um(a) e a posição de menor poder das mulheres. Dessa maneira, analisam que embora os estereótipos anteriormente explicitados estejam relacionados às mulheres, os textos pesquisados pouco falaram sobre as razões de a prática da suposta alienação parental se dar por elas.

11 Conceito abordado pelos autores com base em FACIO, Alda. Hacia outra teoria crítica Del Derecho. In: Género y Derecho. Santiago: LOM Ediciones, 1999. 
Nessa linha de reflexão, apesar da explícita defesa ética da profissão contra qualquer forma de opressão, indagamos se Serviço Social também estaria "insensível" às relações sociais de gênero e de raça ${ }^{12}$. Compreendemos que afinar a análise da realidade social a partir do conceito de relações de gênero se coloca como fundamental, especialmente no contexto do judiciário brasileiro que, apesar de vir assumindo algumas defesas inovadoras, é uma instituição conservadora representativa da supremacia masculina, heterossexual, branca.

\section{Breves apontamentos do serviço social sobre relações soci- ais de gênero e sexo}

Para discussão das relações sociais de gênero e de sexo na realidade brasileira, uma das principais fontes é Heleieth Safiotti ${ }^{13}$, que tem discutido o tema desde os anos 1960. Contudo, considerando os limites deste texto e, em especial, seu diálogo com assistentes sociais, optamos por fundamentar nossas análises em autores que, sendo acadêmicos(as) do Serviço Social, pensaram a questão a partir desse âmbito. Entre esses(as) autores(as), destacamos: Mirla Cisne, Vanessa Bezerra e Renato Veloso.

Bezerra e Veloso (2015, p. 6-8) desmistificam críticas persistentes sobre a cegueira do marxismo às questões de gênero, recuperando como Marx e especialmente os autores marxistas trouxeram a questão da desigualdade entre homens e mulheres, nos limites de seu tempo histórico, momento em que o proletariado é que emergia como central na sociedade capitalista. A autora e o autor demarcam a importância das feministas não marxistas para o debate, por desenvolverem a compreensão de gênero enquanto um fenômeno relacional, que diz respeito tanto a homens como a mulheres, ampliando a análise, até então existente, que tendia para a polarização mulher-vítima e homem-vilão. Tomam o método materialista, constituído pelo princípio da totalidade e da historicidade, como o mais adequado para desnaturalizar a subordinação da mulher e apreender o padrão específico de relações estabelecidas na sociedade capitalista entre

\footnotetext{
12 Se o estudo das relações de gênero se mostra complexo, o das relações raciais tem sido ainda mais desafiador, diante do legado da suposta democracia racial brasileira e da dificuldade das pessoas da raça branca em compreender e abordar as particularidades da branquitude que implica em privilégios. Expressão disso é a dificuldade que temos de incluir no estudo social o quesito raça-cor.

13 Safiotti, socióloga marxista brasileira, referência central para os estudos da categoria gênero, desde a década de 1960, realizou pesquisas sobre a condição da mulher demarcando na perspectiva crítica, a relação de "novelo" entre patriarcado-racismocapitalismo.
} 
mulheres e homens, mulheres e mulheres e homens e homens. Compreendem que as relações de gênero articuladas às de classe e raça/etnia são eixos básicos que estruturam a realidade social. Assim, a categoria analítica gênero se torna útil para compreensão das desigualdades das relações sociais, se imbricada com as demais.

Mirla Cisne (2015), tomando a perspectiva marxista, compartilha do entendimento de que as dimensões de sexo e de raça são fundamentais para a compreensão da classe social, tomando como objeto de sua pesquisa o desenvolvimento da consciência de classe por parte das mulheres, numa sociedade demarcada pelo patriarcado-racismo-capitalismo. Explicita suas inquietações sobre o conceito de gênero ocultar o sujeito político mulher, diluir a relação de hierarquia entre os sexos e outras desigualdades estruturais, como as de classe social. Não sendo autoexplicativo, o uso do termo gênero, dificultaria sua compreensão pela maioria das mulheres que vivência a opressão de sexo. No entanto, ressalta que o uso da categoria não implica necessariamente ausência de perspectiva crítica, como se observa na produção de várias pesquisadoras feministas marxistas, a exemplo de Safiotti. Nesse contexto, apesar de destacar os aspectos positivos que a categoria gênero trouxe para o debate da opressão da mulher, Cisne (2014) adotou o uso do termo relações sociais de sexo, fundamentado em grande parte pelo feminismo materialista francófono.

O conceito de relações sociais de sexo ${ }^{14}$ está vinculado diretamente aos estudos sobre a divisão sexual do trabalho, categoria fundamental para a perspectiva feminista marxista. A subordinação das mulheres aos homens é um dos elementos fundantes da divisão social e sexual do trabalho já que elas, em sua maioria, têm sido designadas à esfera da reprodução, enquanto eles, à esfera da produção.

Esse é um aspecto importante a ser considerado em nossos estudos/ perícias sociais. Compreender a divisão sexual do trabalho durante a união conjugal é condição importante para apreensão das transformações familiares que incidem sobre homens, mulheres e crianças a partir da separação.

\footnotetext{
14 Segundo Devreux (2005, p. 564), socióloga francesa feminista, a utilização do conceito de gênero "permitiu às pesquisadoras francesas serem percebidas como menos agressivas, menos 'feministas', por suas instituições e por seus colegas homens. [...] É também o que permitiu [...] que pesquisadores homens ingressassem nesta área de pesquisa científica, tornada, assim, mais consensual". Mas, para a autora é fundamental "a nomeação da confrontação entre duas classes de sexo. Não pode haver relação social com uma categoria única. Não pode haver relação social sem confrontação”.
} 
Já instigada a superar o estágio da "insensibilidade ao gênero" indagamos: A defesa do compartilhamento da guarda vem a ser, de fato, uma pauta feminista a ser incorporada pelo Serviço Social no Brasil? Como a profissão poderia se posicionar sobre a alienação parental nesse momento de possível revisão da legislação? Como a categoria das relações sociais de gênero pode contribuir com nossos estudos/perícias sociais? Com essa direção, vamos dialogar com a produção de pesquisadoras feministas, tanto do Brasil como de outros países.

\section{Guarda compartilhada e alienação parental: interesse da criança ou expressão da dominação masculina mascarada pela busca da igualdade parental?}

Ainda que a reivindicação feminista crítica tenha sido a liberação da mulher do trabalho doméstico por meio de serviços públicos que o efetivem, certamente é coerente com essa pauta a divisão das atividades relativas à reprodução social entre homem e mulher, rompendo com a demarcação de papel homem-pai-provedor e mulher-mãe-provedora-cuidadora. Resta compreendermos se a guarda compartilhada de filhos(as), para além da igualdade no plano formal, realmente a efetiva.

Thurler (2017), socióloga brasileira, demarca o paradoxo do poder masculino que se faz presente no judiciário brasileiro. Se por um lado existe a deserção da paternidade, por outro, há a disputa pela guarda de filhos(as). Tendo pesquisado o índice de pessoas sem o registro paterno na certidão de nascimento, reflete sobre o ranço patriarcal predominante no que se refere aos deveres em relação as(os) filhas(os). Apesar de a legislação permitir que a mãe, desde 1992, indique o nome do pai da criança para que o cartório o convoque a se manifestar sobre o registro, continua deixando ao homem a prerrogativa de afirmar ou não a paternidade. Parcela deles sequer atende as intimações do judiciário, resultando em processos que se arrastam por anos, sem que as crianças tenham seu direito fundamental garantido.

Em referência à situação de mulheres que perderam a guarda de filhos(as) por alienação parental, após terem denunciado os pais por suposição de ocorrência de abuso sexual, a autora enfatiza a consolidação da lei de alienação parental como fruto do patriarcado e da misoginia, que sobrepõe o valor da palavra do homem ao da mulher. 
A hierarquia entre homens e mulheres persiste, com valorização desigual da palavra de uns e de outras. A palavra da mulher não tem credibilidade diante do Estado patriarcal brasileiro, seja em casos de reconhecimento da paternidade, em que o pai indicado pela mãe se torna "suposto" pai para o Direito, seja em outras situações como violências, estupro, abusos sexuais ou ainda a própria alienação parental. (THURLER, 2017, p. 168).

A autora pondera que a normatização jurídica do compartilhamento da guarda e a da alienação parental se deu a partir do esvaziamento do suporte legal do patriarcado. De fato, se considerarmos a subalternidade da mulher ao marido explicitada no Código Civil de 1916 e as conquistas posteriores - advindas do Estatuto da Mulher Casada (1962), da Lei do Divórcio (1977), da igualdade de direitos e deveres entre homem/pai e mulher/mãe, instituída pela Constituição Federal (1988) e, especialmente, da proteção contra a violência doméstica garantida pela Lei Maria da Penha (2006) - fica evidenciado esse esvaziamento do suporte legal da dominação masculina e o cenário favorecedor para a criação de organizações em defesa dos direitos de homens-pais. Tais organizações exerceram forte pressão junto ao Legislativo para a promulgação da Lei da Guarda Compartilhada e da Lei de Alienação Parental ${ }^{15}$.

Se por um lado, não se pode ignorar essa demanda como expressão legítima dos pais em conviverem e cuidarem dos(as) filhos(as), superando a centralidade sócio histórica da mãe nesse exercício; por outro, não podemos desconsiderar sua articulação com interesses de preservação econômico-patrimonial e de poder masculino.

Nessa linha de reflexão, Tornquist (2008), historiadora feminista, no registro da entrevista realizada com Dufresne, jornalista e ativista do movimento de homens pró-feministas no Canadá, contextualiza que na realidade de maior avanço feminista em Quebec, onde o compartilhamento da guarda ocorre desde a década de 1980, o movimento de pais pela igualdade parental emergiu como expressão da reação conservadora a tal avanço.

Martin Dufresne não hesita em referir-se a esse braço paternal do masculinismo como um movimento de direita, chamando atenção para as correlações diretas entre a não aceitação do direito de escolha da mulher quanto à manutenção do casamento (já que a guarda conjunta não pode ser analisada sem considerar direito ao divórcio) e as violências que, en-

\footnotetext{
${ }^{15}$ Esse histórico foi registrado por Lima (2016) e pelo NUDEM (2019).
} 
quanto fenômeno social, seguem produzindo maridos agressores e mulheres agredidas. (TORNQUIST, 2008, p. 616)

Dufresne evidencia que o movimento pela guarda conjunta, como uma medida legal generalizada, expressa "visceral oposição do masculinismo" à possibilidade da mulher se divorciar, o que entende como risco para mães e filhos(as), pois enquanto os homens podem continuar desconsiderando suas responsabilidades, as mulheres perderiam o poder de escolha de sair do relacionamento, por quererem proteger seus filhos. (Ibid, 2008, p. 624)

Denyse Côté (2016), socióloga canadense feminista, pesquisou a complexidade que envolve a guarda compartilhada, considerando-a como expressão das recentes evoluções de gênero por possibilitar maior mobilidade e pluralidade de experiências para as mulheres.

Ela significa o surgimento e a consolidação da individualidade das mulheres dentro da família. Por esta e outras razões, muitas mães estão felizes pelo acordo de guarda compartilhada que possuem. Elas ficam liberadas do fardo de serem mães solteiras e os filhos mantêm contato contínuo com os pais. Os pais, por sua vez, podem permanecer envolvidos no cuidado diário da criança após o divórcio, muito mais que a geração de pais divorciados que os precedeu. (CÔTÉ, 2016, p. 182-198)

Entretanto, a autora alerta para a importância de romper com a idealização da guarda compartilhada, concluindo que não se pode associá-la automaticamente à igualdade de gênero. A seu ver, um acordo de guarda não é parâmetro de igualdade ou desigualdade, já que as situações sociais e familiares são muito mais complexas. Esclarece que essa falsa simetria de gênero se origina na natureza invisível do cuidado de crianças, cabendo ainda à mulher a maior parte das tarefas do cuidado cotidiano (escovar os dentes, dar banho, vestir, levar para a escola ou creche, etc.) que, na melhor das situações, é compartilhada. Porém, aquelas que implicam planejamento a médio e longo prazo (compra de equipamentos esportivos, planejamento, férias, consultas médicas, apoio financeiro, etc.), ficam a cargo exclusivo das mães. A elas também cabe a gestão das atividades de cuidado "fora de seu tempo familiar", enquanto os pais geralmente contam com a ajuda do novo cônjuge, dos avós e até das ex-esposas. (ibid., 2016, p. 182-198)

$\mathrm{Na}$ França, outro país que revela avanços feministas, onde mães e pais contam com retaguarda econômica e de serviços para cuidados com filhos(as), 
foi aprovada em 2001 a lei de residência alternada das crianças após a separação conjugal.

Devreux (2006, p. 610) - socióloga francesa que, como já referenciamos, discute o conceito das relações sociais de sexo e como elas se expressam na vida das famílias, esclarece que tal aprovação foi resultante do movimento de pais divorciados, da larga disseminação da ideia da "nova paternidade" e da falsa noção de que todos os pais se ocupam dos cuidados de suas crianças tanto quanto as mães.

A partir do levantamento realizado periodicamente na França, por meio do qual são registradas, no decorrer de um dia, as atividades realizadas por homens e mulheres, (profissionais, domésticas, parentais, associativas, lúdicas etc...), a autora pondera que:

As mulheres continuam a realizar $2 / 3$ do trabalho doméstico e parental, ou seja, o dobro da parte assumida pelos homens que - "novos pais" ou não -, depois de dez anos, só reservam a essas atividades mais dez minutos por dia. Assim, as mulheres consagram em torno de 30 horas semanais aos cuidados da casa e dos filhos, enquanto os homens consagram em torno de 15 horas. [...] O estudo mostra que eles são tentados a deixar de trabalhar alguns meses na chegada de um primeiro filho (entretanto, fazem-no 10 a 13 vezes menos do que as mães suecas), mas, feita a experiência, eles não a repetem com um segundo ou terceiro filho. (DEVREUX, 2006, p. 615)

No encadeamento dessa constatação, Devreux conclui que a reivindicação dos homens à igualdade parental, após o divórcio, surge como exigência de concessão de direitos, independente de deveres e se mascara pela defesa dos interesses da criança. Apesar da noção de "novos pais" existir no plano ideológico, dissociada da divisão do trabalho entre os sexos, não significa, entretanto, que não tenha ocorrido mudança na mentalidade dos homens. A seu ver, os pais já não são estranhos ao cotidiano de filhos(as), porém, quando responsáveis pelo cuidado, escolhem atividades que remetem ao "desenvolvimento intelectual [...] preferencialmente, jogos, trabalho escolar ou passeios". Com isso, a autora conclui que a "divisão sexual do trabalho não muda nem de estrutura, nem de significação social" e as atividades ordinárias, relativas ao cotidiano da criança, permanece sem valor social. (DEVREUX, 2006, p. 620)

Nessa linha de reflexão e, para a qual também corroboram outras pesquisas da autora que indicam que quanto maior o número de filhos, aumenta o 
tempo de dedicação do pai ao trabalho, constata-se que se para os pais existe a prerrogativa de escolherem em que momento e de que forma se ocuparão de filhos(as), para as mães não há escolhas.

[...] Novos pais ou não, os homens continuam a escolher em que momento e em que condições eles se ocupam com suas crianças, assumindo, de fato, parcialmente suas responsabilidades parentais diante do conjunto da sociedade e demandando a ela reconhecimento de prerrogativas iguais às das mulheres que não fazem escolhas: quaisquer que sejam as condições, o cuidado com as crianças lhes incumbe, tenham elas ou não outros campos de atividade. (DEVREUX, 2006, p. 622)

O alerta de Côté sobre a romantização presente na defesa da guarda compartilhada nos provocou. Como assistente social que realiza cotidianamente estudos/perícias sociais em disputa de guarda de filhos(as), identificamos essa tendência, especialmente por também estarmos ancoradas no "melhor interesse da criança" que, nessa situação, se referiria ao direito fundamental de conviver com o ramo materno e paterno de suas origens, enriquecedor para sua socialização e ampliação da proteção social. (GOIS; OLIVEIRA, 2019)

A respeito do "melhor interesse da criança", concordamos com a ponderação de Thurler (2017, p. 175) de que seja uma "expressão onipresente nas varas de família, mas que tem revelado um conceito impreciso, com diferentes interpretações, conforme valores e representações de quem o emprega". Não apenas o Serviço Social, mas especialmente o Direito, faz uso recorrente desse princípio, que precisa ser consubstanciado para que não resvale para juízo de valor.

É sabido que a família é local de proteção, mas também o principal espaço de reprodução de violências de gênero e de geração. Entretanto, foi a partir do estudo das relações de gênero e das autoras feministas que nos atentamos para o quanto tendemos a reproduzir, na apreensão de nosso objeto profissional, a fragmentação posta na instituição. Enquanto na Vara Criminal o recorte é na violência contra a mulher e filhos(as) com vistas a protege-los e criminalizar o responsável, na Vara de Família o foco é a decidir qual dois (pai ou mãe) pode melhor atender as necessidades e direitos dos (as) filhos(as) e como regulamentar o convívio. A família que vivencia a violência doméstica, da qual decorre a separação e parte das disputas de guarda e regulamentação de convívio, será atendida em instâncias fragmentadas, desconsiderando-se que essas demandas expressam uma totalidade. 
Inseridas na esfera cível da Justiça de Família, com o foco na garantia do direito fundamental da criança, concluímos estar explorando insuficientemente os sentidos da violência doméstica para a família, correndo até mesmo o risco de sua banalização, tal como apontado por Côté (2016, p. 182-198) que explicita que “[...] os profissionais, sejam advogados, psicólogos ou assistentes sociais, também influenciam grandemente o processo, em geral sobrevalorizando os benefícios da guarda compartilhada e banalizando a violência doméstica".

Côté (2016) pondera que, no contexto de violência doméstica, até mesmo o acordo feito pela mulher para o compartilhamento da guarda, não pode ser considerado como uma escolha voluntária, tendo em vista a assimetria de poder e as consequências negativas para elas que se prolongam nos momentos de visita dos(as) filhos(as).

Simioni (2017), advogada, pesquisadora brasileira, também na perspectiva das relações de gênero, realizou sua pesquisa de campo por meio de consulta da jurisprudência sobre guarda e do acompanhamento de audiências judiciais. Ela reitera a ideia de que sob o pretexto de atender o princípio do melhor interesse da criança, a vivência da violência que também impacta filhos(as), é totalmente desconsiderada, cabendo a essa mulher, como mãe, superá-la e, ainda, viabilizar o convívio dos(as) filhos(as) com o pai.

Recai sobre as mulheres a superação do trauma da violência doméstica para possibilitar a manutenção da parentalidade masculina. Então, individualmente, ela tem de superar a violência doméstica e, ainda, possibilitar que os filhos convivam com o pai agressor. Aparece novamente, aqui, a "fórmula mágica" do superior interesse da criança, justificando a necessidade de as mulheres superarem, por si, o trauma da violência doméstica. (SIMIONI, 2017, p. 183)

No encerramento do diálogo com essas pesquisas ficou ainda mais evidenciada a importância de avançarmos no Brasil em pesquisas sobre as práticas judiciárias, a partir de dados indicativos das dimensões de gênero presentes na realidade social e os resultados das decisões judiciais para a vida dos membros das famílias.

Esse estudo evidencia que o compartilhamento da guarda não necessariamente contribui para a equidade parental, podendo até mesmo ser instrumento de reprodução de violência de gênero e de geração. Ilumina também a compreensão de que punição/criminalização da alienação parental, além de ter gerado volume ainda maior de demanda ao judiciário, atende a interesses adul- 
tocêntricos colidentes com a proteção integral de crianças e adolescentes. Isso não quer dizer que não existam mulheres/mães que façam uso do poder advindo de sua proximidade e relação cotidiana com filhos(as) para cercear o convívio entre eles(as) e os pais. Mas para enfrentar tais situações, concordamos com a ponderação do Conanda (2018), de que já existem indicativos suficientes nas legislações, restando aos juízes(as) tomarem a decisão que lhes compete.

E ainda, é preciso destacar que no caso brasileiro, não precisamos de mais leis, mas de condições objetivas para os cuidados de filhos(as) e de serviços públicos que contribuam, inclusive, para dar suporte aos impactos advindos da separação que atinge homens, mulheres e crianças de várias classes. Mas, para o poder público certamente é funcional e também lucrativo manter a estrutura judiciária afogada pelos embates entre Kramer x Kramer ${ }^{16}$ que, para acessarem a justiça da família já passaram pelo filtro da classe-raça-gênero. A alegação de alienação parental tem movimentado incansavelmente a máquina judiciária, por parte daqueles que podem arcar com custos de profissionais, especialmente do Direito e da Psicologia que chegam, inclusive, a se "especializar" nesse tema.

\section{Considerações finais}

Para as considerações finais, vamos refletir sobre a contribuição que a categoria relações de gênero ou sexo pode oferecer para os estudos/perícias sociais nas demandas da Justiça de Família e sobre a possibilidade dessa abordagem representar parcialidade profissional no processo judicial demarcado pelo direito ao contraditório.

A análise das relações de gênero ou sexo, pautada na categoria da divisão social e sexual do trabalho, certamente subsidia a identificação de aspectos socioeconômicos e, especialmente, os culturais, que tendemos a não contemplar em nossos estudos/perícias sociais, chaves importantes de conhecimento sobre os indivíduos sociais, tal como posto por Fávero (2009).

Em Gois e Oliveira (2019), ponderamos que o compartilhamento da guarda poderia ser tomado como um norte para nossos estudos/perícias sociais, afinal nossa defesa é a do compartilhamento de tarefas domésticas entre homens e mulheres. Já alertávamos para a necessidade de levar em consideração, na perspectiva da equidade, possível desigualdade de poder na relação conjugal

\footnotetext{
${ }^{16}$ Filme americano de 1979 que discute o esforço do homem/pai para cuidar do filho após a mãe decidir deixá-los. Com sua volta, ocorre a disputa da guarda entre pai e mãe.
} 
e parental, inclusive, violência doméstica, o que contra indicaria o compartilhamento.

Na perspectiva da primazia do interesse da criança, assumimos a defesa do direito à convivência familiar de filhos/as com os dois ramos de sua origem como fundamental para a sua socialização, pertença e proteção social, considerando sua fase de desenvolvimento. Para tanto, mais uma vez atentamos para a necessidade de compreensão do estabelecimento das relações de gênero, especialmente, entre pai e mãe, além das relações geracionais - de pai e mãe com filhas(os). Que devem se pautar mais no atendimento das necessidades das pessoas em desenvolvimento do que no das pessoas adultas, ainda que, muitas vezes, elas estejam extremamente articuladas. (ibid., 2019)

Nessa linha de discussão, apontamos como indicativos para o estudo/ perícia social a contextualização social da vivência conjugal e a análise dos pactos estabelecidos para a organização familiar na vigência da união conjugal, assim como da organização de vida pós-separação, com vistas a apreendermos possíveis reproduções de desigualdades no âmbito da ocupação profissional, de rendimentos, das relações de gênero no casamento (assimetrias de poder na definição de questões da vida familiar, como a administração de atividades domésticas e das relações com o meio social), autoritarismo ou até violências nas relações parentais, além de outras associadas a questões étnico-raciais. (GOIS; OLIVEIRA, 2019, p. 100)

Embora já tivéssemos desenvolvido um pouco o olhar a partir das relações de gênero, o estudo das pesquisadoras feministas, sobretudo sobre a guarda compartilhada, nos impactou e contribuiu para ampliarmos a compreensão sobre as contradições postas na realidade social das famílias e na aprovação das leis mencionadas. Especialmente a noção do esvaziamento legal do patriarcado, que limitou o poder masculino sobre mulher e filhos(as) e contribuiu para a reação masculinista numa perspectiva conservadora. Articulando ainda a possibilidade de separação da mulher com a de denúncia da violência doméstica sofrida ${ }^{17}$, no caso brasileiro da Lei Maria da Penha (2006), faz sentido a persistência na perspectiva punitiva da Lei de Alienação Parental (2010) em alinhamento com a compreensão de que as relações sociais de sexo envolvem o confronto entre duas categorias de sexo pela preservação de seus interesses.

Indagando-nos acerca da indignação masculina, especialmente frente a possibilidade de escolha da mulher por separar-se, viabilizada a partir da legali-

\footnotetext{
17 É importante registrar que a denúncia da violência não se dá da mesma forma por mulheres brancas e negras.
} 
zação do divórcio, passamos a lembrar de inúmeras famílias com as quais trabalhamos, em que homens e também filhos(as) expressavam intenso sofrimento frente a dificuldade em aceitar essa escolha da mulher/mãe, muitas vezes rompendo a relação com elas. Essa constatação também se articula com dados que indicam que as mulheres se destacam nos pedidos litigiosos de divórcio ${ }^{18}$.

$\mathrm{O}$ aprofundamento do estudo das relações sociais de gênero permitiu superarmos o receio de assumirmos partido da mulher/mãe na realização do estudo/perícia social, inviabilizando a busca da "imparcialidade possível" frente ao direito contraditório da defesa na ação judicial que ambos têm (pai e mãe). Bezerra e Veloso (2015, p. 25) nos lembram que a definição de Marx sobre categorias de conhecimento da realidade social, são apropriações mentais de uma dinâmica existente no próprio objeto. Assim, o uso dessa categoria permite a identificação de desigualdade poder e opressão entre homens e mulheres, historicamente construída e, portanto, presente na sociedade, para além das relações familiares. Embora o poder de opressão, inscrito na sociedade patriarcal capitalista, seja o masculino, não significa que as mulheres/mães não o exerçam, a partir inclusive da centralidade do convívio com filhos(as) construída sócio-historicamente no marco do capitalismo industrial. E ainda, que a reprodução da ideologia patriarcal, conforme já ponderado, ocorra para além das relações homem-mulher.

A teórica feminista negra, norte americana, bell hooks ${ }^{19}$ (2019), contribui para essa reflexão, expondo uma questão difícil mas necessária de ser encarada pelo movimento feminista - a violência contra crianças, não apenas por parte dos homens/pais mas das mulheres/mães que, como já sabemos, são as que mais se encarregam de seus cuidados. Na lógica de reprodução da dominação do patriarcado, crianças "não têm direitos" e são "propriedades de pai e mãe, para que façam com elas o que bem entenderem". Para a autora a "[...] a teoria feminista ainda não ofereceu nem crítica feminista nem intervenção feminista, quando a questão é violência da mulher adulta contra criança”. (HOOKS, 2019, p. 110-111)

A autora explicita a contradição observada no feminismo quando o assunto é a maternagem. "Pensadoras feministas individuais que criticaram o determinismo biológico em todas as outras áreas, com frequência aderiam a ele quando o assunto era maternagem. Elas não foram capazes de aderir completa-

${ }^{18}$ Em 2010 de 56.126 pedidos de divórcios, 18.849 foram não consensuais. Desses, as mulheres requereram em 13.297 casos. Os homens, em 5.552. (IBGE, 2010).

${ }^{19}$ Uso do nome próprio em minúsculo é escolha da autora. 
mente à noção de que os pais são tão importantes e sabem exercer a parentalidade tão bem quanto elas." (ibid., p. 123). Nessa linha de reflexão, fica claro como a discussão sobre guarda compartilhada e alienação parental não pode se reduzir às críticas antagônicas parciais dos movimentos dos pais e os das mães.

Dessa forma, concluímos que a categoria das relações sociais de gênero e de sexo, articuladas às de classe e raça, certamente potencializam a leitura e a análise da realidade social e contribuem para o enfrentamento das armadilhas postas pelas demandas na Justiça de Família.

\section{Referências}

BAPTISTA, M. V. Pesquisa social, prática profissional e interdisciplinaridade. Emancipação, Ponta Grossa, v. 1, n. 10, p. 395-401, 2010.

BATISTA. T. B. Judicialização dos conflitos intrafamiliares: considerações do Serviço Social sobre a alienação parental. 168 fls. Dissertação de Mestrado, Centro de Ciências Jurídicas e Econômicas, Programa de Pós-Graduação em Política Social - Universidade Federal do Espírito Santo, Vitória, 2016.

BEZERRA, V.; VELOSO, R. Gênero e Serviço Social: Desafios a uma abordagem crítica. Editora Saraiva, São Paulo, 2015.

BORGIANNI, E. Identidade e autonomia do trabalho do/a assistente social no campo sociojurídico. In: CONSELHO FEDERAL DE SERVIÇO SOCIAL. II SEMINÁRIO NACIONAL: O SERVIÇO SOCIAL NO CAMPO SOCIOJURÍDICO NA PERSPECTIVA DA CONCRETIZAÇÃO DE DIREITOS. Anais... Brasília: CFESS, 2012. P 164-176.

BORGIANNI. E. Para entender o Serviço Social na área sociojurídica. Revista Serviço Social e Sociedade, São Paulo, n. 115, p.407 - 442, set. 2013.

BRASIL. Código Civil. Lei $\mathbf{n}^{\circ} \mathbf{3 . 0 7 1}$, de $\mathbf{1}^{\circ}$ de janeiro de 1916. Disponível em: <http://www.planalto.gov.br/ccivil 03/LEIS/L3071.htm>. Acesso em: 14 dez.2020.

. Lei n. 4.121, de 27 de agosto de 1962. Dispõe sobre a situação jurídica da mulher casada. Disponível em: < $\underline{\text { http: / /www2.camara.leg.br/legin/fed/ }}$ lei/1960-1969/lei-4121-27-agosto-1962-353846-publicacaooriginal-1-1.html $>$.

Acesso em: 14 dez. 2020.

Lei n. 6.515, de 26 de dezembro de 1977. Regula os casos de dissolução da sociedade conjugal e do casamento, seus efeitos e respectivos processos, e dá outras providências. Disponível em: < $\underline{\text { http:/ / www.planalto.gov.br/ }}$ 
ccivil 03/LEIS/L6515.htm>. Acesso em: 14 dez. 2020.

. Constituição (1988). Constituição da República Federativa do Brasil. Brasília, DF: Senado, 1988.

. Lei n. 10.406, de 10 de janeiro de 2002. Novo Código Civil. Disponível em: < http://www.planalto.gov.br/ccivil 03/Leis/2002/110406.htm>. Acesso em: 14 dez. 2018.

Lei n. 11.340, de 07 de agosto de 2006. Lei Maria da Penha. Disponível em: <http://www.planalto.gov.br/ccivil 03/ Ato2004-2006/2006/ Lei/L11340.htm. > Acesso em: 14 dez.2020.

. Lei $\mathbf{n}^{\circ} \mathbf{1 1 . 6 9 8}$, de 13 de junho de 2008. Institui e disciplina a guarda compartilhada. Disponível em: <http://www.planalto.gov.br/ccivil 03/ ato2007-2010/2008/lei/l11698.htm.>. Acesso em: 14 dez. 2020.

. Lei Federal $\mathrm{n}^{\circ} \mathbf{1 2 . 3 1 8}$, de 26 de agosto de 2010. Dispõe sobre a alienação parental. Disponível em: < http://www.planalto.gov.br/ccivil 03/ _ato2007-2010/2010/lei/112318.htm\#: : :text=Disp \%C3\%B5e \%20sobre $\% 20 \mathrm{a}$ $\% 20$ aliena $\% \mathrm{C} 3 \% \mathrm{~A} 7 \% \mathrm{C} 3 \% \mathrm{~A} 3 \mathrm{O} \% 20$ parental, $13 \% 20 \mathrm{de} \% 20$ julho $\% 20 \mathrm{de}$ \%201990.> Acesso em: 14 dez. 2020.

Lei $\mathbf{n}^{\mathbf{0}} \mathbf{1 3 . 0 5 8}$, de 22 de dezembro de 2014. Estabelece o significado da expressão "guarda compartilhada" e dispõe sobre sua aplicação. Disponível em: <http://www.planalto.gov.br/ccivil_03/_ato2011-2014/2014/lei/ 113058.htm. >. Acesso em: 14 dez. 2020.

. IBGE. Estatísticas do Registro Civil. 2010.

. IBGE. Estatísticas do Registro Civil. 2017.

CISNE, M. Relações Sociais de Sexo, "raça"/etnia e classe: uma análise feminista-materialista. Temporalis, Brasília, ano 14, n. 28, p. 133-149, jul./dez. 2014.

Feminismo e consciência de classe no Brasil. São Paulo: Cortez, 2015.

CONANDA. Nota Pública do sobre a Lei da Alienação Parental. Brasília, 2018. Disponível em: < http://www.conselho.crianca.df.gov.br/wp-content/ uploads/2018/10/

Nota 0548496 Nota Publica sobre a Lei de Alienacao Parental FI-

NAL.pdf $>$ Acesso em14 dez.2020.

CONSELHO FEDERAL DE PSICOLOGIA. Debatendo sobre Alienação: diferentes perspectivas. CPF, 2019. Disponível em $:<\underline{\text { https://site.cfp.org.br/pu- }}$ 
blicacao/debatendo-sobre-alienacao-parental-diferentes-perspectivas/ $>$. Acesso em 14 dez.2020.

CONSELHO REGIONAL DE SERVIÇO SOCIAL. Nota Técnica Posição Preliminar sobre Serviço Social e Mediação de Conflitos. CRESS-SP, 2016. Disponível em: < http://cress-sp.org.br/wp-content/uploads/2016/03/ cress nota mediacao online.pdf. $>$ Acesso em 14 dez.2020.

CÔTÉ, D. Guarda Compartilhada e Simetria nos Papéis de Gênero: novos desafios para a igualdade de gênero. Revista Observatório, v. 2, n. 3, p. 182-198, ago. 2016.

DEVREUX, A.- M. A teoria das relações sociais de sexo: um quadro de análise sobre a dominação masculina. Sociedade e Estado, Brasília, v. 20, n. 3, p. 561 584, dez. 2005.

- A paternidade na França: entre igualização dos direitos parentais e lutas ligadas às relações sociais de sexo. Sociedade e Estado, Brasília, v. 21, n. 3 , p. 607-624, Dec. 2006.

FÁVERO, E. Instruções sociais de processos, sentenças e decisões. In:

CFESS/ABEPSS (org.). Serviço Social: direitos sociais e competências profissionais. Brasília: CFESS/ABEPSS, 2009. p. 609-636.

GOIS, D. A.; OLIVEIRA, R. C. S. Serviço Social na Justiça de Família: demandas contemporâneas do exercício profissional. São Paulo: Cortez, 2019.

HOOKS, b. O feminismo é para todo mundo: políticas arrebatadoras. 8. ed. Rio de Janeiro: Rosa dos Tempos, 2019.

HÜMMELGEN, I.; CANGUSSÚ, K. J. Estereótipos de gênero no direito das famílias: um estudo da doutrina jurídica sobre alienação parental. ENADIR, FFLCL-USP, São Paulo, 2017.

IAMAMOTO, M. V. Questão social, família e juventude: desafios do trabalho do assistente social na área sociojurídica. In: SALES, M. A.; MATOS, M. C.; LEAL, M. C. (orgs.) Política social, família e juventude. São Paulo: Cortez, 2004. p. 261-298.

. A Questão Social no capitalismo. Temporalis, Brasília, ano II, n. 3, jan/jul. 2011.

LIMA, E. F. R. Alienação Parental sob o olhar do Serviço Social: limites e perspectivas da atuação profissional nas Varas de Família. 2016. 243 fls. Tese de Doutorado, Programa de Estudos Pós Graduados em Serviço Social, Pontifícia Universidade Católica de São Paulo, São Paulo, 2016. 
MIOTO, R. C T. Família, trabalho com famílias e Serviço Social. SERV. SOC. REV., Londrina, v. 12, n. 2, p. 163-176, jan./jun. 2010

MONTAÑO, C. Alienação parental e guarda compartilhada: um desafio ao Serviço Social na proteção dos mais indefesos - a criança alienada. Rio de Janeiro: Lumen Juris, 2016.

NETTTO, J. P. A Construção do Projeto ético: político frente à crise contemporânea. In: CURSO DE CAPACITAÇÃO EM SERVIÇO SOCIAL E POLÍTICA SOCIAL, I, 1999, Distrito Federal, Brasília, Anais... : CFESS/ CRESS/ ABEPSS/ CEAD, 1999.

NUDEM. Nota Técnica nº 01/2019 Análise da Lei Federal 12.318/2010 que dispõe sobre "Alienação Parental”. Núcleo de Defesa da Mulher da Defensoria Pública do Estado de São Paulo, 2019.

PAULA, V. A análise da categoria mediação na prática profissional do assistente social nas Varas de Família e Sucessões do Tribunal de Justiça do Estado de São Paulo. 2015.247 fls. Dissertação de Mestrando, Programa de Estudos Pós Graduados em Serviço Social, Pontifícia Universidade Católica, São Paulo, 2015.

SIMIONI, F. 15 Anos do Novo Código Civil de 2002 e a Garantia dos Direitos das Mulheres: famílias, guarda compartilhada e a síndrome da alienação parental. In: Consórcio Lei Maria da Penha pelo Enfrentamento a Todas as Formas de Violência de Gênero contra as Mulheres (org.), Tecendo fios das críticas feministas ao Direito no Brasil, 2017. p.177-185.

THURLER. A. L. 15 Anos do Novo Código Civil de 2002 e a Garantia dos Direitos das Mulheres: famílias, guarda compartilhada e a síndrome da alienação parental. In: Consórcio Lei Maria da Penha pelo Enfrentamento a Todas as Formas de Violência de Gênero contra as Mulheres (org.), Tecendo fios das críticas feministas ao Direito no Brasil, 2017. p.165-177.

TORNQUIST, C. S. Em nome dos filhos ou "o retorno da lei do pai": entrevista com Martin Dufresne. Revista Estudos Feministas, Florianópolis, mai/ ago.2008. Disponível em: < https://dx.doi.org/10.1590/S0104026X2008000200016>. Acesso em: 02 jan. 2020. 